\title{
A brief introduction to the use of event-related potentials in studies of perception and attention
}

\author{
GEOFFREY F. WOODMAN \\ Vanderbilt University, Nashville, Tennessee
}

\begin{abstract}
Because of the precise temporal resolution of electrophysiological recordings, the event-related potential (ERP) technique has proven particularly valuable for testing theories of perception and attention. Here, I provide a brief tutorial on the ERP technique for consumers of such research and those considering the use of human electrophysiology in their own work. My discussion begins with the basics regarding what brain activity ERPs measure and why they are well suited to reveal critical aspects of perceptual processing, attentional selection, and cognition, which are unobservable with behavioral methods alone. I then review a number of important methodological issues and often-forgotten facts that should be considered when evaluating or planning ERP experiments.
\end{abstract}

Electroencephalogram (EEG) recordings were the first method developed for direct and noninvasive measurements of brain activity from human subjects (Adrian \& Yamagiwa, 1935; Berger, 1929; Jasper, 1937, 1948). By noting when stimuli were presented and when tasks were performed, early researchers examining the raw EEG sought to characterize the changes in the state of electrical activity during sensory processing and the performance of simple detection tasks (e.g., P. A. Davis, 1939; Walter, 1938). However, when scientists began to take advantage of signal averaging, the event-related potential (ERP) technique quickly became the primary tool of the cognitive neuroscientist (Cooper, Winter, Crow, \& Walter, 1965; H. Davis, 1964; Donchin \& Cohen, 1967; Donchin \& Lindsley, 1969; Spong, Haider, \& Lindsley, 1965; Sutton, Braren, Zubin, \& John, 1965; Sutton, Tueting, Zubin, \& John, 1967; Walter, Cooper, Aldridge, McCallum, \& Winter, 1964). Despite the rise of modern neuroimaging methods, several advantages of the ERP technique continue to make it one of the most widely used methods to study the architecture of cognitive processing.

The primary goal of this tutorial is to introduce researchers who are unfamiliar with ERPs to their use, interpretation, and dissemination in studies of sensation, perception, attention, and cognition. I hope that the uninitiated readers will become better consumers of ERP research. For those who plan to conduct ERP research and to add human electrophysiology to your methodological toolbox, I strongly urge you to read the more detailed resources that are afforded the space to cover the theoretical and practical issues with which the practicing electrophysiologist should be familiar (Handy, 2005; Hillyard \& Picton, 1987; Luck, 2005; Nunez \& Srinivasan, 2006; Regan, 1989; Rugg \& Coles, 1995). ${ }^{1}$

I will cover three general topics in this tutorial. First, I will provide an extremely brief review of the biophysical basis of the EEG and the averaged ERPs, which makes them ideal for studying perception and attention. Second, I will present advice for conducting and evaluating ERP studies that test specific hypotheses. Third, I will discuss several often forgotten characteristics of ERPs that should be considered when designing new experiments and interpreting ERP findings. The topics covered here were selected on the basis of my experience reviewing and publishing manuscripts in which findings from ERP experiments were reported. A large number of ERP experiments, including my own, that have serious trouble during the review process are in such a state because the waveforms do not afford unambiguous interpretation resulting from one or more of a handful of common problems. Before discussing the characteristics that readers should look for in ERP studies, I will quickly review some basics about this electrophysiological technique.

\section{Why ERPs Are Well Suited to \\ Study Perception and Attention}

With their spectacular spatial resolution, it is reasonable to ask why imaging techniques have not made ERPs obsolete. The most direct answer to this question is simple: time. By time, I mean that ERPs have a temporal resolution that allows for the measurement of brain activity from one millisecond to the next, and many aspects of attention 
and perception appear to operate on a scale of tens of milliseconds. Because the brain is essentially a wet electrical device, these electrophysiological recordings provide a direct measure of the currency of the system that we study. Also, given the nature of electrical activity and the tissue in which ERPs are generated and propagated, there is no measurable conduction delay between the brain activity generated inside the head and the potentials recorded from the scalp (Nunez \& Srinivasan, 2006).

What exactly generates the voltage fluctuations recorded outside the head? We operate under a working hypothesis that appears to account for a number of observations. Early electrophysiologists hypothesized that the EEG and intracranially recorded field potentials (localfield potentials) were due to postsynaptic activity of neural ensembles (Adrian \& Yamagiwa, 1935; Li, McLennan, \& Jasper, 1952). This view is widely accepted today (Logothetis, Pauls, Augath, Trinath, \& Oeltermann, 2001; Luck, 2005; Nunez \& Srinivasan, 2006), although the biological basis of the EEG and ERPs has been periodically debated (e.g., Fox \& O'Brien, 1965; Galambos \& Jahasz, 1997). This means that instead of recording a summation of the action potentials generated by individual neurons, we believe that the EEG and averaged ERPs measure electrical potentials generated in the extracellular fluid as ions flow across cell membranes and neurons talk to one another via neurotransmitters.

To create electrical fields large enough to propagate through the brain, dura, skull, and skin, a large number of neurons must be active simultaneously (i.e., in the ballpark of $10^{7}$ neurons; see Cooper et al., 1965; Ebersole, 1997). In addition, this large group of neurons needs not only to be active synchronously, but also to have a geometry that is perpendicular to the surface of the skull and not canceled out by other neuronal ensembles active at the same time and with an opposite orientation (Luck, 2005; Nunez \& Srinivasan, 2006). The simultaneously active neurons must have approximately the same orientation for the potentials to summate, and this means that ERPs are primarily generated by the postsynaptic potentials of cortical pyramidal cells (which are perpendicular to the cortical surface). Given the location and orientation of a specific neural generator in the brain, we can predict the pattern of voltage that will be observed across the head. This is known as the forward problem and is easily solved - unlike its evil twin, the inverse problem. The inverse problem states that if we are given a distribution of electrical potential across a volume conductor, like the head, we cannot know where it is generated if we do not know the number of simultaneously active generators a priori (Helmholtz, 1853). Practically, this means that we cannot definitively localize the neural generators of ERP effects within the head from the data recorded outside of it. Thus, the outstanding temporal resolution of ERPs comes with the cost of living with an unknown degree to spatial resolution.

Although the inability to resolve the activity of individual neurons may seem like a large drawback of the ERP technique, it appears that the functional unit of analysis that ERPs measure fortuitously maps on to the cognitive processes that psychologists frequently hypothesize about. Specifically, ERPs allow us to observe a series of cognitive operations that take place from before the delivery of sensory information to the peripheral nervous system until even after a behavioral response is made. The earliest studies showed that stereotyped fluctuations in potential were elicited by the presentation of sensory stimuli (e.g., P. A. Davis, 1939). However, ERP research really gained popularity when a study demonstrated that the cognitive activity related to preparing for a task could be measured. The contingent negative variation (CNV) was shown to build up prior to the onset of a stimulus to which participants were required to respond (Walter et al., 1964). It is fitting that this anticipatory effect was the first of the ERP components indexing cognitive processes discovered in the modern era (see also Kornhuber \& Deecke, 1965). This era is marked by the advent of averaging together potentials time locked to an observable event and recorded on multiple trials to extract the small-amplitude voltage fluctuations common to each trial from the much larger amplitude EEG noise in which they are embedded (Dawson, 1954; Donchin \& Heffley, 1975; Donchin \& Lindsley, 1969; Galambos \& Sheatz, 1962). This same period saw the development of the 10/20 system for standardized electrode placement, which made ERP findings far easier to integrate and replicate across studies (Jasper, 1958).

The peaks and troughs of a stimulus-locked ERP waveform allow us to visualize cognitive processing as it unfolds during a trial. Figure 1 shows idealized waveforms time locked to the presentation of a visual stimulus during a target discrimination task. First things first, note that voltage is plotted with negative going up. Stories about the origin of this convention abound. It is clear that this method of presentation has been and continues to be a contentious issue as efforts have been made to flip the voltage axis (Bach, 1998; Luck, 2005). In my own work, I follow the decades-old convention of plotting negative up for practical reasons. Specifically, the vast majority of ERP researchers have plotted their waveforms with negative going up, and perceptual learning has made such waveforms significantly easier for me to interpret than those with negative plotted down.

The series of voltage fluctuations shown in Figure 1 index a sequence of processes as the brain transforms information from raw sensory input to the appropriate behavioral response. First, we see the $\mathrm{C} 1$ component, which flips polarity on the basis of whether the eliciting stimulus appears in the upper or lower visual field and which is believed to be generated by activity in the primary visual cortex (Clark, Fan, \& Hillyard, 1995; Clark \& Hillyard, 1996; Estevez \& Spekreijse, 1974; Jeffreys \& Axford, 1972). This initial deflection is followed by the $P 1$ and $\mathrm{N} 1$ components as information propagates through the visual system and perceptual analysis is performed (Heinze et al., 1994; Heinze, Mangun, \& Hillyard, 1990; Luck, 1995; Vogel \& Luck, 2000). ${ }^{2}$ Next, we can observe waveforms elicited by the deployment of covert attention to peripheral targets in the visual field (e.g., the N2pc; Eimer, 1996; Luck \& Hillyard, 1994a, 1994b) and components associated with categorization of the visual stimulus (e.g., 


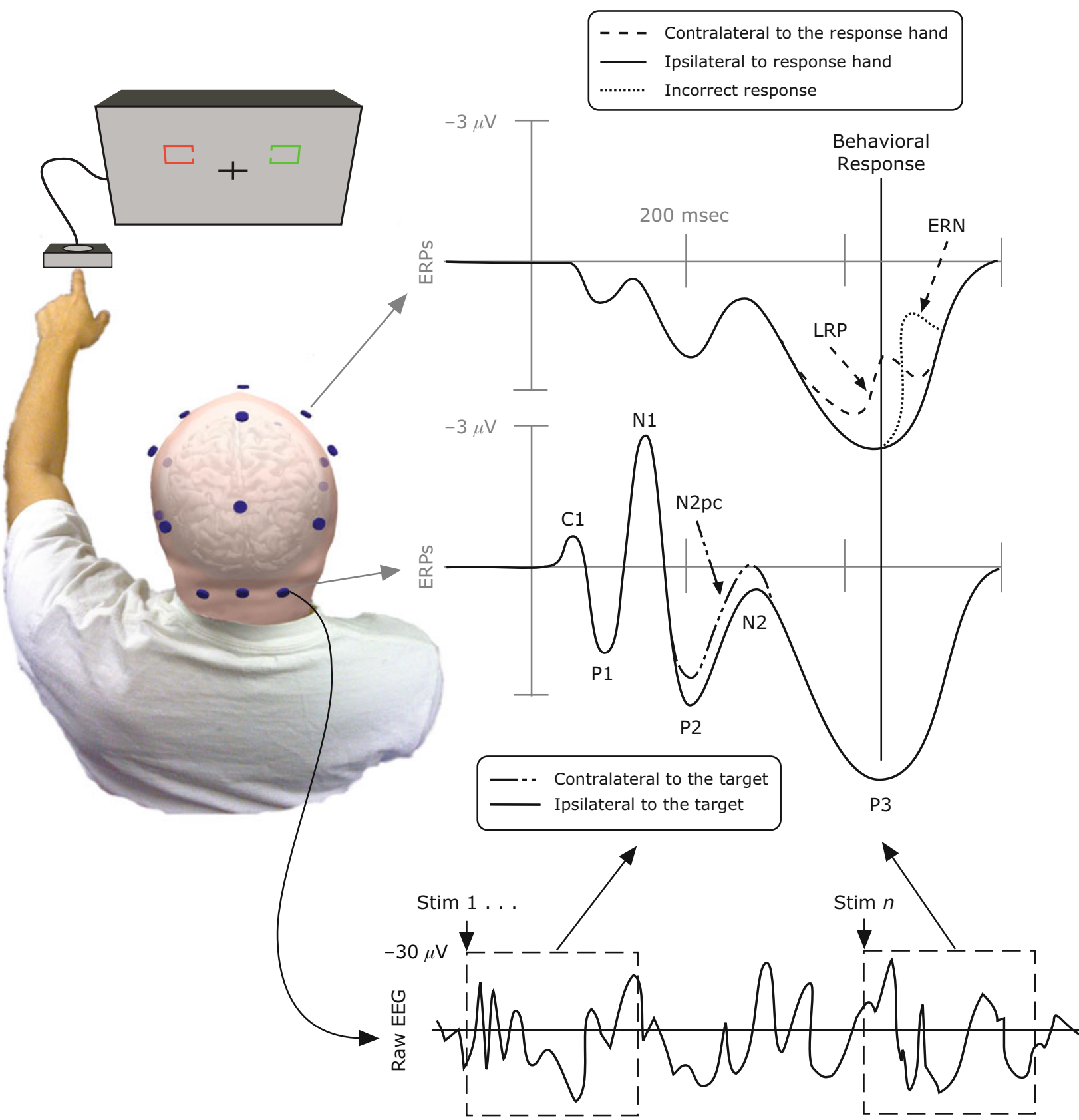

Figure 1. Idealized event-related potential (ERP) waveforms elicited during a visual search task. The left panel shows a bilateral stimulus array to which the waveforms are time locked and a model of the human head with the placement of a subset of electrodes from the 10/20 system. The bottom right panel illustrates how ERPs are extracted from the raw electroencephalogram (EEG). The middle right panel shows the classic sequence of ERP components elicited during a visual task with left visual field targets at occipitotemporal electrode sites. The top right panel shows the sequence of ERP components observed during the performance of the task requiring a response with a finger on the left hand that could be either correct or incorrect. Note that the P3 and ERN components are not typically lateralized but, instead, have fairly broad scalp distributions with central maxima.

the N2/P3 complex; Kutas, McCarthy, \& Donchin, 1977; Pritchard, Shappell, \& Brandt, 1991; Sutton, 1979; Sutton et al., 1965). Waveforms indexing working memory encoding and maintenance are the next to come online (i.e., the P3 and contralateral-delay activity [CDA]; Donchin, 1981; Vogel \& Machizawa, 2004), followed by components elicited during the selection and preparation of the motor response (i.e., the lateralized readiness potential
[LRP]; Coles, 1989). Even after the participant completes the behavioral response and the trial is ostensibly over, the ERPs show us that cognitive processing continues. For example, waveforms elicited after the behavioral response are related to evaluating performance on the trial that just occurred (e.g., the error-related negativity and error positivity [ERN and Pe, respectively]; Falkenstein, Hoormann, Christ, \& Hohnsbein, 2000). 
An ERP component can be simply defined as one of the component waves of the more complex ERP waveform. ERP components are defined by their polarity (positiveor negative-going voltage), timing, scalp distribution, and sensitivity to task manipulations. Different ERP component nomenclatures emphasize different aspects of these defining features, and to provide a jumping off point for literature reviews, I describe several in Table 1. Also note that although we frequently discuss a component as a unitary entity (e.g., the N2 or P3), it is probably more accurate to describe a given component as belonging to a family of components with similar polarities and temporal characteristics (e.g., Johnson, 1986; Pritchard et al., 1991). An average ERP waveform can be time locked to any externally observable event, with the primary reference events being the presentation of a stimulus and the execution of a behavioral response. The bottom of Figure 1 illustrates how the small ERP components are embedded in the background EEG, which is at least an order of magnitude larger. The idealized ERP waveforms shown in Figure 1 would take hundreds or even thousands of trials from a number of participants to approximate through averaging and do not capture the amount of latency jitter that the components and reaction times exhibit. Finally, the term component also has deeper meanings that generally refer to the underlying cognitive processes and brain activity indexed by the potential (for detailed discussions, see Luck, 2004, and Rugg \& Coles, 1995). One reason that ERP studies of attention and perception continue to flourish is that they rest on a foundation of decades worth of basic research on ERP components.

I provide this brief and simplified overview of a handful of the most prominent ERP components to make the point that the foundational work of early ERP researchers provided the current generation with a toolbox overflowing with instruments measuring process-specific activity in the working brain. Figure 2 illustrates how auditory stimuli elicit a somewhat different series of ERP components, including very early waveforms that actually begin with potentials generated in the brain stem (Hillyard \& Picton, 1987). But the ability of ERPs to show the progression of information processing in the brain is qualitatively similar, regardless of sensory modality and task (e.g., Desmedt, Huy, \& Bourguet, 1983; Pratt, in press). This ability to measure the dynamics of processing in the brain through the sequence of ERP components has made this technique a vital tool for testing theories of perception, attention, and cognition.

Table 1

Summary of Event-Related Potential Components Using a Variety of Nomenclatures During a Simple Visual-Manual Task Similar to That of Figure 1

\begin{tabular}{|c|c|c|c|c|c|c|}
\hline Nomenclature & Ordinal & $\begin{array}{l}\text { Latency } \\
\text { (Peak) }\end{array}$ & $\begin{array}{c}\text { Scalp } \\
\text { Distribution }\end{array}$ & $\begin{array}{l}\text { Task/Stimulus } \\
\text { Specificity }\end{array}$ & $\begin{array}{c}\text { Hypothesized } \\
\text { Process(es) Indexed }\end{array}$ & Useful Reference \\
\hline $\begin{array}{l}\text { Components preceding } \\
\text { a stimulus }\end{array}$ & & & & $\begin{array}{l}\mathrm{CNV} \\
\text { (O- \& E-waves) }\end{array}$ & $\begin{array}{l}\text { anticipation, cognitive } \& \\
\text { motor preparation }\end{array}$ & $\begin{array}{l}\text { Brunia, van Boxtel, \& } \\
\text { Böcker (in press) }\end{array}$ \\
\hline \multirow{8}{*}{$\begin{array}{l}\text { Components following } \\
\text { a stimulus }\end{array}$} & $\mathrm{C} 1$ & $\mathrm{P} / \mathrm{N} 50-70$ & & & sensory processing & Pratt (in press) \\
\hline & $\mathrm{P} 1$ & P90-100 & & & $\begin{array}{l}\text { sensory/perceptual } \\
\text { processing }\end{array}$ & Pratt (in press) \\
\hline & N1 & N170-200 & $\begin{array}{l}\text { posterior } \\
\text { versus } \\
\text { anterior N1 }\end{array}$ & N170 for faces & $\begin{array}{l}\text { perceptual processing, } \\
\text { expert recognition, visual } \\
\text { discrimination }\end{array}$ & $\begin{array}{l}\text { Hillyard, Vogel, \& Luck } \\
\text { (1998); Rossion \& Jacques } \\
\text { (in press); Vogel \& Luck } \\
\text { (2000) }\end{array}$ \\
\hline & $\mathrm{P} 2$ & & & & not well understood & Crowley \& Colrain (2004) \\
\hline & $\mathrm{N} 2$ & $\mathrm{~N} 225-250$ & & & $\begin{array}{l}\text { object recognition, } \\
\text { categorization }\end{array}$ & $\begin{array}{l}\text { Folstein \& Van Petten } \\
\text { (2008); Pritchard et al. } \\
\text { (1991) }\end{array}$ \\
\hline & P3 & P300 & $\mathrm{P} 3 \mathrm{a} / \mathrm{P} 3 \mathrm{~b}$ & $\mathrm{P} 3 \mathrm{a} / \mathrm{P} 3 \mathrm{~b}$ & $\begin{array}{l}\text { stimulus evaluation time, } \\
\text { categorization, context } \\
\text { (working memory) } \\
\text { updating, cognitive load }\end{array}$ & Polich (in press) \\
\hline & & & $\mathrm{SPCN}$ & CDA & $\begin{array}{l}\text { maintenance in visual } \\
\text { working memory }\end{array}$ & Perez \& Vogel (in press) \\
\hline & & & & LRP & response preparation & Smulders \& Miller (in press) \\
\hline \multirow[t]{2}{*}{$\begin{array}{l}\text { Components following } \\
\text { a response }\end{array}$} & & & $\begin{array}{l}\text { medial } \\
\text { frontal } \\
\text { negativity }\end{array}$ & $\begin{array}{l}\text { ERN/Ne \& } \\
\text { FBN }\end{array}$ & $\begin{array}{l}\text { error processing, } \\
\text { reinforcement learning or } \\
\text { response conflict signal }\end{array}$ & $\begin{array}{l}\text { Gehring, Liu, Orr, \& Carp } \\
\text { (in press) }\end{array}$ \\
\hline & & & & $\mathrm{Pe}$ & $\begin{array}{l}\text { affective or conscious } \\
\text { assessment of task } \\
\text { performance }\end{array}$ & Falkenstein et al. (2000) \\
\hline
\end{tabular}

Note-This list is focused on visual components and neglects components from the auditory, language, and memory literatures. CNV, contingent negative variation; O- \& E-waves, orienting \& expectancy waves; C1, Component 1; N, negative; P, positive; N2pc, N2 posterior contralateral; PCN, posterior contralateral negativity; CDA, contralateral-delay activity; SPCN, sustained posterior contralateral negativity; LRP, lateralized readiness potential; ERN/Ne, error-related negativity/error negativity; FBN, feedback negativity; Pe, error positivity. 


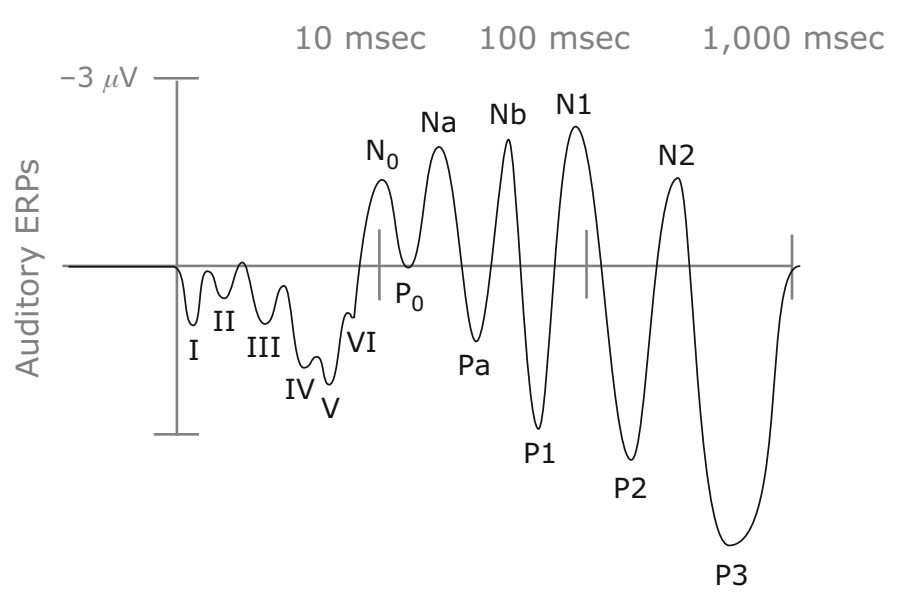

Figure 2. Idealized event-related potential (ERP) waveform evoked by a brief auditory stimulus. Waveforms shown would be expected from a central electrode site (i.e., $\mathrm{Cz}$ ). Note that the waveforms are plotted as a function of log time.

\section{Fundamentals of Rigorous ERP Studies}

I now turn to a discussion of the features of effective studies of attention and perception using ERPs. Conversely, the most common problems that I have observed in submitted manuscripts, conference presentations, and published reports are instances of experiments that violate these rules of thumb. I do not pretend that this is a comprehensive list or that I have had sufficient longevity in the field to rank these issues by importance. Instead, I list them here in approximately the order of frequency that I have encountered them in my own studies and those of others.

A long history can be a blessing and a curse. Given the massive literature on which new ERP studies can draw, the majority of ERP studies are designed to isolate and measure modulations of specific ERP components. This can mean measuring a number of different ERP components during the same task (e.g., Vogel, Luck, \& Shapiro, 1998). More often, studies are focused on a specific ERP component during a variety of hypothesis-driven task manipulations (e.g., Woodman \& Luck, 2003a, 2003b). New ERP components are still being discovered (e.g., Bach \& Meigen, 1992; Klaver, Talsma, Wijers, Heinze, \& Mulder, 1999; Luck \& Hillyard, 1994b) and the significance of existing ERP components reinterpreted (e.g., Vogel \& Luck, 2000). However, many articles are submitted that tout the discovery of a new ERP component or novel modulation but do not actually report something new. This is the cost of using a technique with such a long history and rich literature. When digging in ancient ground, we need to be careful not to rediscover the triumphs of previous teams of archeologists.

A related issue is that a number of ERP studies are conducted in which the researchers do not test predictions about how specific ERP components will behave in a certain experimental paradigm. Some of these have been important and groundbreaking (e.g., Hillyard, Hink, Schwent, \& Picton, 1973; Otten, Quayle, Akram, Ditewig, $\&$ Rugg, 2006). However, avoiding the approach of tailor- ing experimental designs to focus on specific components, thus failing to take advantage of the wealth of componentbased research, is a risky endeavor. As was just discussed, this can lead to the rediscovery of known components and phenomena. In addition, those that engage in exploratory studies sometimes record and compare ERPs elicited by physically different stimuli while observers perform different tasks. This naturally results in ERP waveforms that differ in many ways, across many different time points. Besides leading to the statistical problem of multiple comparisons, it becomes very difficult to determine the critical locus of the behavioral effects. Are the stimuli processed differently at an early point in time, with these early differences propagating through the system, or does the crucial difference in information processing that causes the behavioral effects occur later in the trial?

Nothing should be happening when nothing is happening. When I get a new ERP manuscript to read, the first thing that I do is flip to the figures and look at the baseline period of the waveforms (e.g., -200 to $0 \mathrm{msec}$ relative to stimulus onset). I do this because examining the differences in the waveforms before anything has happened provides a quick way to assess the noise level in the averaged potentials. If the stimuli and trial types were randomized, the brain response prior to the presentation of the stimuli should not differ between types of trials. When there are differences between the waveforms before the trial begins, this is a clear sign that the signal-to-noise ratio of the averages is low or that some kind of confound is present. ${ }^{3}$

Many times, articles are submitted and even published that describe the significance of stimulus-elicited activity, despite the fact that the amplitudes of the effects of interest are similar in magnitude to differences in the baseline. In Figure 3, I show an example of waveforms in which the prestimulus noise is at least as large as the P1 and N1 modulations based on the task relevance of the stimuli presented. We have no reason to believe that these potential effects are real, because they are approximately 


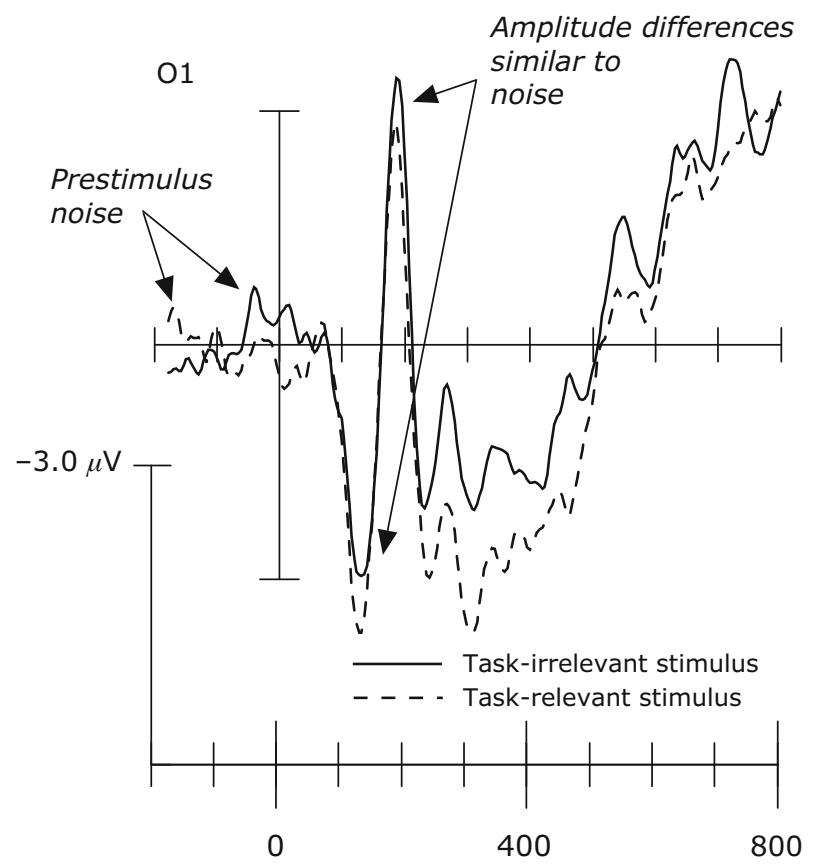

Time Poststimulus (msec)

Figure 3. Example of a waveform in which the prestimulus noise is equal in amplitude to the potential effects of interest. These are actual data recorded from electrode $\mathrm{O} 1$ and averaged across 2 participants with approximately 150 artifact-free trials elicited by each type of stimulus, to illustrate the need for sufficient power and clean baselines.

the same size as the differences found before information has even reached the retina or left the retina en route to the brain (i.e., less than $30 \mathrm{msec}$ after stimulus onset). Consumers of ERP research or those preparing their research for consumption should be wary of waveforms showing effects that are not bigger than the noise, even if it is possible to find a measurement window that will produce significance. Moreover, reviewers should insist that a prestimulus baseline period of at least $100 \mathrm{msec}$ be shown in the figures.

I mentioned in the brief introduction to ERP components that preparatory activity is observed even before an imperative stimulus appears. Researchers interested in how the brain perceives new inputs and allocates attention are rarely interested in its ability to predict when the next trial will begin. For this reason, ERP researchers usually take two countermeasures to remove such anticipatory activity that could contaminate or simply obscure the stimuluselicited waveforms. The first is randomization, and the other is baseline correction. Randomization of the trial types and stimulus sequence, along with sufficient signal averaging, removes the possibility that the anticipatory ERP components can be differentially active preceding the different trial types. Baseline correction is also ubiquitous in ERP methodology. Simply put, baseline correction means subtracting the voltage measured during a prestimulus window (e.g., -200 to $0 \mathrm{msec}$ relative to stimulus onset) from the entire waveform, so that the waveform re- flects the voltage relative to the average prestimulus voltage. This is done so that the anticipatory effects, like the CNV, will not distract readers from the important effects elicited following the stimulus presentation.

It is possible that you would like to record ERPs during a paradigm that involves presenting stimuli in fairly rapid succession. As I will discuss more below, the waveforms and effects elicited by a stimulus last for at least a second. This means that the baseline interval immediately prior to the onset of a critical stimulus might overlap with waveforms elicited by a preceding stimulus. In this case, it would be prudent to show a longer epoch that precedes the onset of the stimulus sequence or, at least, precedes the presentation of the critical stimuli that distinguish the trial types. In addition, reviewers might not only ask you to show a sufficient baseline period to assess the noise level in your ERP waveforms, but also request that you show more of your waveforms than just the first several hundred milliseconds following a stimulus to assess the reach of your experimental manipulation.

Collect as many trials from each participant as you can. Imagine that you are reading an ERP article and the baselines of the ERP waveforms contain voltage deflections of the same magnitude as the effects of interest described later in the article. How could the researchers have avoided reporting these unconvincing results? The only solution to this problem is to improve the signal-tonoise ratio. This usually means relying on signal averaging across a larger number of trials and making an experiment much longer than it would take if only the behavioral data were collected.

One of the most useful things that can be learned through training in an ERP laboratory is that the number of trials that are typically necessary to accurately measure a specific ERP component depends on your component of interest. The early visual ERP components, like the C1, $\mathrm{P} 1$, and $\mathrm{N} 1$, are in the same frequency range as the largest source of noise in the human brain. That noise source is the alpha-band activity $(8-12 \mathrm{~Hz})$ that dominates the EEG. ${ }^{4}$ Alpha waves are particularly large when an observer is sleepy or bored (i.e., during an ERP experiment) and abate significantly when a stimulus is presented (Berger, 1929; Pfurtscheller, Stancák, \& Neuper, 1996). As a rule of thumb, to get a good measure of the $\mathrm{C} 1$ from an individual participant, it can take over 1,000 artifact-free trials per condition (i.e., per cell of the experimental design) because of alpha noise, its small amplitude, and substantial overlap with the P1 component. The P1 and N1, which are frequently of interest to perception and attention researchers, can require $300-1,000$ trials per condition to measure reliably. For the N2pc component, I try to obtain 250 trials per condition per participant. In comparison, the large and slow $\mathrm{P} 3$ component can be measured with only about 35-60 trials per condition from each participant. I have found these ballpark values to be very handy when planning new ERP experiments that require a modest number of observers (i.e., <15). I need to point out that if you are running an ERP experiment that allows you to collect fewer trials from each participant than you would like, it should be possible to compensate for this by collecting 
data from a large number of participants. In addition, if your recording environment is virtually noiseless and your participants are very attentive, trial numbers smaller than these might be workable (see more on how to achieve this below). However, Figure 3 illustrates that the early components used in studies of perception and attention are unlikely to be interpretable with significantly fewer trials from individual participants than the estimates provided above.

It would be great if it were possible to filter ERP data and remove noise without distorting or removing the signal of interest. As was described above, much of the frequency content of the ERP components is in exactly the same frequency band as the noise. This means that no filter settings exist that will remove the noise without wiping out a significant portion of the signal itself. In addition, the more aggressively we filter our ERP waveforms, the more we cause unintended distortions of the amplitude - and, potentially, the timing - of the signals (Duncan-Johnson \& Donchin, 1979). This is particularly unfortunate, given that precise timing and amplitude measurements are the very reasons for recording ERPs in the first place.

There are at least three methods that I would suggest for eliminating noise at the front end of data acquisition that can increase your signal-to-noise ratio. First, shield your electrodes from environmental noise by recording in a radio-frequency shielded room or chamber and placing equipment powered by alternating current in Faraday cages (see chap. 8 in Luck, 2005). Second, randomly jitter the exact timing of the intertrial interval to ensure that the alpha-wave activity of the participant does not become phase locked with the stimulus presentation rate. Third, you can reduce noise in your recordings by keeping your participants as alert and engaged in the task as possible. This is because alpha-band noise increases when participants are drowsy and bored (i.e., precisely the conditions under which most of us collect our data).

I use three tricks that help encourage participants to remain engaged in the task throughout the experiment. One trick is to use short blocks of trials with ample time for the participants to take breaks during the experiment. The second is to provide participants with refreshing caffeinated beverages during these breaks in the tasks. The third trick is to provide an additional type of stimulation during the experimental trials themselves. In particular, I encourage my participants to listen to music during visual experiments. Because the onset of the visual stimuli are jittered and not in phase with the prosody of the music, the brain activity generated when processing this music is averaged out while reducing the amplitude of alpha noise. Informal analyses have shown that listening to music improves signal-to-noise ratios without changing the patterns of effects observed during visual ERP experiments. Of course, if you are studying the processing of auditory or linguistic stimuli or the ability to multitask, playing music for your participants might not be possible. In summary, these dietary and environmental sources of enrichment reduce noise levels in the raw EEG and keep the number of trials that must be averaged together down to a minimum.
Why blinks and eye movements corrupt your data. The largest single electrical dipole in the head is the corneoretinal potential, which points from the back of the eye toward the front of the eye. This means that when you are recording the EEG and the time-locked ERPs, even a fairly small eye movement or blink will cause a massive electrical transient (e.g., a typical eyeblink is over $100 \mu \mathrm{V}$, compared with only $1-2 \mu \mathrm{V}$ for a typical P1 wave). For example, when I began recording EEG from monkeys, the first test of the new hardware was to verify that I could see these eye movement artifacts online in the raw EEG.

When you are interested in using ERPs to study how stimuli are perceived or attended, it is critical to ensure that your findings are not simply due to contamination by eye movements. The idea that electrophysiological findings can be explained by oculomotor behavior is not new (Walter, 1938), nor does it seem that we have stopped finding potentially interesting effects that might simply be due to even small eye movements (e.g., Yuval-Greenberg, Tomer, Keren, Nelken, \& Deouell, 2008). The electrical artifact caused by a blink or saccadic eye movement of more than $1^{\circ}-2^{\circ}$ is fairly large (approximately $16 \mu \mathrm{V}$ per degree of eye movement) and can be detected with electrooculogram (EOG) recordings (Hillyard \& Galambos, 1970; Lins, Picton, Berg, \& Scherg, 1993). These EOG recordings are good at detecting blinks and changes in eye position caused by saccades relative to fixation but are not sensitive to slow shifts in fixation that accumulate across trials (e.g., when the task-relevant stimuli always appear at the same peripheral location). When fixation of an absolute position is necessary, we must use an eyetracker in conjunction with the EEG recording. Eye movements can also be a problem when auditory (or other modality) stimuli are presented, because visual attention is automatically drawn to the source of such signals (e.g., McDonald, Teder-Sälejärvi, \& Hillyard, 2000) and the eyes often follow attention's lead (Hoffman \& Subramaniam, 1995; Kowler, Anderson, Dosher, \& Blaser, 1995).

One approach to address the problem of trials contaminated by blinks and eye movements is to use artifactcorrection procedures (e.g., Berg \& Scherg, 1994). Artifactcorrection procedures can be useful in working with clinical or developmental populations who cannot be expected to maintain fixation when peripheral stimuli are presented (Ille, Berg, \& Scherg, 2002). However, it is always best to exclude trials containing ocular artifacts from ERP averages and analyses. This can also mean needing to replace participants because of excessive eye movements across the experiment (for a two-step procedure of artifact rejection and participant exclusion, see Woodman \& Luck, 2003b).

Rejecting trials with artifacts is the surest way of avoiding ambiguous data, because movements of the eyes not only shift the corneoretinal potential, but also drastically change the input to the visual system. If it were the case that just the former occurred, it would result in voltage changes localized to the orbits. Because shifting the fovea to a different part of the world drastically changes the input to the visual system, the activity across at least half of the cortex will also differ between trials with and 
without eye movements. These visual differences will not have the same time course as the artifact itself because of transmission delays in the visual system, and the distributions will not be focused on the orbits as some artifactcorrection algorithms assume. Thus, to be confident in the conclusions that you draw, it is critical to exclude from ERP averages trials and participants that exhibit evidence of eye movements or blinks.

Different stimuli inherently modulate ERP components. Differences in the amplitudes of ERP components should be expected when different stimuli are presented to observers. This should particularly be the case for the early components related to sensory and perceptual processing (i.e., the $\mathrm{C} 1, \mathrm{P} 1$, or N1). An example is useful to illustrate this point. If you record the ERPs time locked to the presentation of either a white square or a black square of equal sizes, presented at fixation on a gray background, different neurons are activated by those different stimulus onsets (e.g., those with different contrast polarity sensitivities). The differential responses will be present throughout the visual system (Felleman \& Van Essen, 1991; Ungerleider \& Mishkin, 1982). With sufficient power, this will result in sensory ERP components that differ in amplitude for the two stimuli. This result would hardly be surprising, given previous reports in the literature (Ellemberg, Hammarrenger, Lepore, Roy, \& Guillemot, 2001; Luck, 2005; Pratt, in press). However, suppose that you were interested in whether white stimuli are more likely to attract attention to themselves than are black stimuli. A huge number of researchers have reported modulations of the P1 and N1 components due to the allocation of attention to locations and stimuli (Luck, 1995; Mangun \& Hillyard, 1990). It might seem natural to conclude that if the white stimulus elicits a larger amplitude $\mathrm{P} 1$ or N1 component than the black stimulus, this is due to attentional enhancement of the brain's response to the white stimulus. However, this cannot be concluded from the ERP results. Among ERP researchers who study attention, this experimental design is said to have a physical stimulus confound (Hillyard \& Picton, 1987; Näätänen, 1975). That is, the manipulation of presenting physically different stimuli is confounded with any potential modulation by attention.

When someone is interested in how attention influences the processing of stimuli, it is necessary for the stimuli eliciting the waveforms to contribute equally to the averages for the attended and unattended conditions. This means that the stimulus manipulations need to be orthogonal to the manipulation of attention. For example, in the above scenario using white and black squares, the participants could switch between blocks of trials in which the white squares were task relevant and blocks in which the black squares were task relevant. If we take the example of the stimulus array shown in Figure 1, the observers could alternate between blocks of trials in which they search for targets that are colored red and those colored green so that we could determine that the effects of attending to the target location were due to the task relevance of the target color and not to some low-level characteristic like its luminance. In contrast, if someone is interested in the more low-level questions of how the brain responds to different stimuli without simultaneous manipulations of attention, it is entirely appropriate to measure and report how the brain responses differ to stimuli with different physical features (e.g., Eimer, 1998; Thierry, Martin, Downing, \& Pegna, 2007).

Measuring voltage amplitudes and latencies. Another asset that ERP researchers have gained from decades of previous work is how to quantify the observed effects. As was described directly above, when a brighter stimulus is presented, the early visual ERP components exhibit larger amplitude responses. How do we go about quantifying the magnitude of such amplitude effects? One approach is to measure the voltage of an ERP component at its peak or trough. Similarly, researchers have sometimes measured the point in time at which an ERP component reaches its maximum voltage before the voltage returns back to zero. The ERP literature convincingly demonstrates that focusing on these arbitrary local maxima (i.e., positive or negative voltage peaks) is misleading. I will first discuss why measuring the peak is difficult, and potentially uninformative, before presenting the measurement methods that I recommend and use.

Confining your analyses of ERP components to the metrics of the peaks is dangerous for a number of reasons. I will discuss the three problems that loom largest. First, the peak of a component is heavily influenced by highfrequency noise. Figure 4A shows how the timing of the peak of a relatively slow waveform (e.g., a $10-\mathrm{Hz}$ wave, like the P1 or N1 component) can be heavily influenced by bursts of higher frequency noise. As a result, measuring the peak of an ERP component is practically difficult. Even after the observed waveform is digitally low-pass filtered, the peak of the wave can be contaminated by the random fluctuations in the higher frequency noise.

A second deeper question is why you would want to measure the peak of a component in the first place. The peak is an arbitrary feature of an ERP component that could be argued to be less important than its beginning or end (Luck, 2004). Rarely does a debate between cognitive scientists hinge on when a certain process is approximately halfway completed. However, this is essentially what one is trying to quantify when measuring the timing of the peak of an ERP component. I could easily argue that the onset or offset of a component is often a much more critical measurement (e.g., Miller \& Hackley, 1992; Osman, Bashore, Coles, Donchin, \& Meyer, 1992; Renault, Ragot, Lesevre, \& Remond, 1982), although no less difficult to measure (Luck, 2004).

The third problem of measuring component latencies is related to an issue that I sidestepped when discussing the sequence of ERP components. Despite the fact that ERPs have excellent temporal resolution, the precise measurement of the timing of an individual ERP component is made difficult by the fact that ERP components typically overlap with their neighbors. Component overlap is the term used to describe the fact that the voltage fluctuations of the ERP waveform inherently overlap with each other in time and space. For example, the same change in ob- 


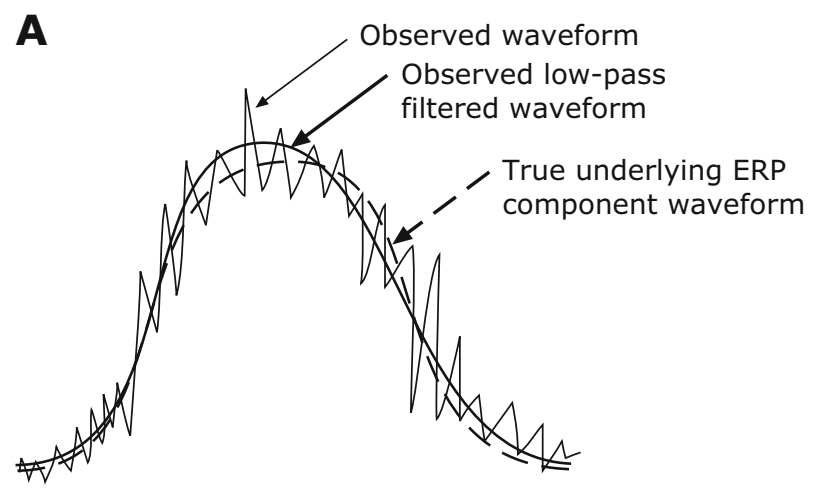

B Peak Voltage Measure

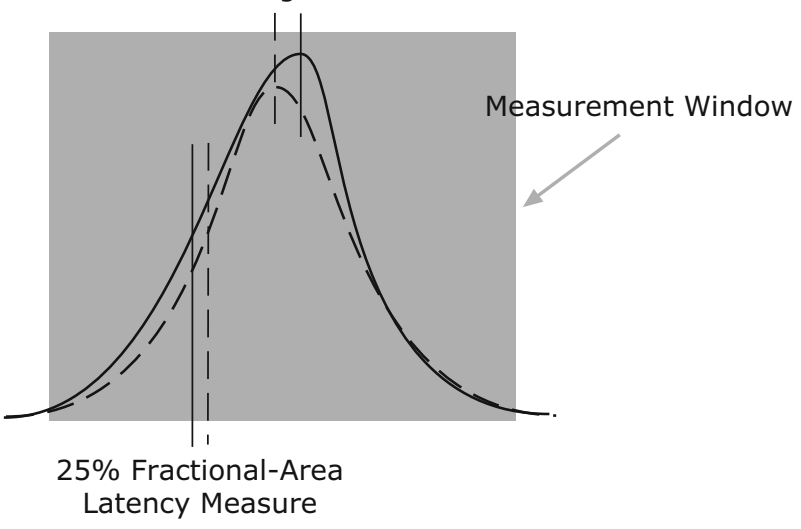

Figure 4. Hypothetical waveforms illustrating the difficulty of measuring the latency of an ERP component from the moment of peak voltage. (A) Demonstration of how high-frequency noise can bias the measurement of latency on the basis of the peak. (B) IIlustration of how measuring peak latency of waveforms in two conditions can lead to patterns qualitatively different from those of the less biased method of measuring fractional-area latency. The gray region shows the measurement window.

served voltage between two conditions could be the result of an earlier offset of the N2 component or an earlier onset of the P3 component (e.g., Näätänen, Gaillard, \& Mäntysalo, 1978; Näätänen \& Michie, 1979). This is a special case of the same potential for simultaneous activity that makes the generators of ERP components difficult to localize. The component overlap problem has been difficult to adequately address with statistical and mathematical analysis techniques alone (Luck, 2005; Rugg \& Coles, 1995). The problems of overlap and susceptibility to highfrequency noise also result in difficulty in measuring voltage amplitude using the peak of an ERP component.

At this point, the reader might feel that this discussion has become depressing, so I will now turn to some positive aspects and the approaches that appear to be the most productive. In some instances, it is possible to isolate specific ERP components by virtue of their unique scalp distributions (e.g., Coles, Gratton, \& Donchin, 1988; Woodman \& Luck, 1999). Although these tend to be exceptions and not the rule, the use of such measures can significantly simplify interpretation. Even without such exotic components, we can use the scalp distribution of ERP effects to help infer the locus of experimental effects. For example, if it appears that an experimental manipulation led to the reduction in the amplitude of the N2 component, we could rule out that the effect is really due to an earlier onset of the P3 by showing that the scalp distribution of the modulation was consistent with the known distribution of the $\mathrm{N} 2$ and not of the P3.

When it comes to quantifying aspects of specific ERP components, it is best to not focus on the peak and, instead, to look more broadly at the component. Specifically, in many influential ERP articles, the features of ERP components have been measured using temporal windows (Luck, 2005). The widths of these windows are set such that they bracket the entire ERP component of interest, across all of the individual participant's waveforms, and are similar to those in previous studies measuring the same component. Sufficient care must be taken in this step of setting the window, because a skewed or narrow setting can taint the measures of timing and amplitude using the window. In practice, a liberal setting of the size of the window (i.e., broad) makes the measurement procedure as conservative as possible relative to analyses focused on the peak, which are driven by selection bias. This procedure applies to measurements of latency as well as amplitude. When measuring latency, the most rigorous method is to use a fractional-area latency metric. This involves measuring when a component achieves some threshold of its total voltage in the window. For example, if I wanted to measure the $25 \%$ fractional-area latency of waveforms from two different conditions, I would measure at what time point $25 \%$ of the area under the voltage curve defined by the measurement window has accrued in each condition.

Figure 4B shows how the fractional-area latency and peak-latency measures could yield qualitatively different results from a pair of hypothetical waveforms. Recall that filtering of ERP waveforms can distort amplitude and possibly latency measurements. As a result, I was taught that all analyses of the timing and amplitude of averaged ERP components should be performed on the unfiltered ERP waveforms passed by the amplifier. Although virtually every published ERP article shows filtered waveforms in their figures, the analyses and measurements will be undistorted by this filtering process if they are performed on the waveforms prior to this step of cosmetic enhancement. Finally, one robust and potentially fruitful approach that I would recommend trying is a fractional-latency measure that works backward from an easy-to-define feature of an ERP component (Kiesel, Miller, Jolicœur, \& Brisson, 2008). This approach offers the promise of providing the advantages of measuring fractional-area latency without the ambiguities in setting the measurement window.

Voltages are measured relative to reference sites. To record a voltage from the scalp, it is sufficient to have one active and one reference electrode. This is because voltage is always the difference in electrical potential between a given electrode and the reference. The mathematics of subtraction mean that electrical activity generated near the reference will appear as an inverted polarity voltage at the active electrode. If we used a two-electrode configuration, as Berger (1929) did, it would not be possible to deter- 
mine whether the activity that we measured was greatest at the site of the reference electrode, the active electrode, or somewhere in between. Early in the history of human electrophysiology, researchers identified the importance of using multiple active electrodes to facilitate interpretation of the recorded voltages and to determine the effect of the distance between the reference electrode and the active electrodes (Walter, 1938). The practical importance of referencing for ERP users is that the voltage measured at active electrode sites closer to the reference site will necessarily be closer to $0 \mathrm{~V}$, all other things being equal.

An implicit assumption is that the reference is at a location that provides a $0-\mathrm{V}$ baseline. However, there is no perfect reference site, because there is no truly electrophysiologically neutral location on the body. In my own laboratory, we use a reference on the right mastoid process (the bone behind your right ear), re-referenced offline to an electrode on the left mastoid. This re-referencing minimizes spatial distortion in the distribution of potentials measured across the head (Luck, 2005; Nunez, 1981) and has the added benefit of being widely used, so that our findings can be compared with those from other labs. The linked mastoids and average reference procedures induce significant spatial distortions in the pattern of potentials measured across the head. Linked mastoids do this by creating a short circuit between the left and right sides of the head, because they are, by definition, linked by low-resistance electrical wire. The average reference procedure induces distortions because of the assumption that the activity across all of the electrodes in the array captures all of the electrical activity generated in the brain (Dien, 1998). Another reference procedure that is sometimes used is to place the reference at $\mathrm{Cz}$, the electrode location at the top and center of the head (i.e., along the anterior-posterior midline). Although there is no electrophysiologically neutral location for the reference, using this location can be particularly problematic in certain situations. I have seen a number of articles in which the researcher was interested in measuring broadly distributed components with fronto- or parieto-central maxima (e.g., the ERN or P3) and in which Cz was used as the reference. Given that we know that the ERP components of interest should be apparent at this electrode location, any effects measured at the active electrodes would be minimized by using the voltage underlying this location as the reference point. This would be like measuring the loudness of your voice in the front row of a Metallica concert.

There are situations in which you need to place the reference near the active electrodes. These are when you are using a bipolar electrode configuration (e.g., Brown \& Norcia, 1997). The logic of this configuration is to have a reference very close to the active electrode to remove all potentials but those occurring between the reference and the active electrode (Nunez \& Srinivasan, 2006). However, the monopolar configurations described above are used in virtually all ERP studies, and common methods are very useful in trying to relate your findings to previous (and future) research. There are several books in which the authors describe why certain reference configurations can be problematic or advantageous (Luck, 2005; Nunez, 1981; Nunez \& Srinivasan, 2006), and these should be consulted for additional details.

\section{Issues That We Rarely Discuss}

There are a number of characteristics of ERP waveforms that were discovered during the first several decades of research and that are now rarely the focus of studies or discussion in articles. I believe that it is useful to discuss these characteristics here, because they often come up in conversations with colleagues and while designing new experiments.

ERP refractoriness. One of the first ERP projects that I collected data for involved measuring the visual N1 component during detection and discrimination tasks (Vogel \& Luck, 2000). During that educational experience, I was informed that early sensory and perceptual components, like the N1, are refractory at short interstimulus intervals (ISIs). In other words, ERP components are reduced in amplitude when the eliciting stimulus follows soon after another stimulus. In this situation, soon is loosely defined. Specifically, Woods, Courchesne, Hillyard, and Galambos (1980; Woods, Hillyard, Courchesne, \& Galambos, 1980) showed that the amplitudes of the N1 and P2, but not the P3, elicited by an auditory stimulus were reduced even when approximately $1 \mathrm{sec}$ had passed since the presentation of the last stimulus as compared with longer ISIs (see also Lu, Williamson, \& Kaufman, 1992). Indeed, it has been proposed that the refractory period of the auditory N1 may last tens of seconds (Nelson \& Lassman, 1973). Although this fundamental characteristic of the ERP components often used to study perception and attention is known to many ERP experts, this feature might be unknown to many fairly new users or readers of ERP articles. It means that the use of short ISIs that allow for more trials to be collected may reduce the size of the components that the researchers seek to harvest. The rule of thumb that I inherited and use in my own laboratory is to temporally space stimulus onsets by approximately $1 \mathrm{sec}$ if at all possible. It deserves mentioning that many interesting paradigms in the attention and perception literatures involve presenting stimuli at different ISIs (e.g., the psychological refractory period paradigm). This means that ERP researchers may misinterpret the inherent refractoriness of the ERP components as being due to more interesting or complex phenomena (e.g., the depletion of cognitive resources). Therefore, when trying to avoid physical stimulus confounds across conditions, we should be careful to equate both the individual stimuli and the ISIs between successive stimuli.

Offset transients. A characteristic of ERPs that I often discuss with collaborators when talking about potential experimental designs is the fact that sudden stimulus offsets elicit ERP components too. This has been an important topic of investigation in the auditory (e.g., Hillyard \& Picton, 1978; Näätänen \& Picton, 1987; Picton, Woods, \& Proulx, 1978a, 1978b) and somatosensory (e.g., Spackman, Boyd, \& Towell, 2006) modalities. Although it is documented and known among ERP research- 
ers interested in human vision (e.g., Crevits, van Lith, \& Viifvinkel-Bruinenga, 1982; Woodman, Arita, \& Luck, 2009), the nature of the ERP response to visual offsets has received less attention. Instead, it is recognized as a potential confounding factor in that offsets elicit a series of sensory evoked components (i.e., P1 and N1) similar to those observed following the onset of a visual stimulus. Methodological sources in which this issue is discussed recommend presenting visual stimuli so briefly that no distinct offset response is visible (typically $200 \mathrm{msec}$ or less for visual stimuli) or for sufficiently long intervals that the offset response to a stimulus does not overlap with the onset-elicited components (Luck, 2005). The perceptual and neurophysiological underpinnings of the offset response to sensory stimuli are fertile grounds for investigation. It is possible that a better understanding of these effects could yield tools for the investigation of pathwayspecific activity in the visual system or the specificity of deficits in clinical disorders.

Individual differences. Perhaps the best known, yet least well documented, facet of participants' ERP components is the existence of individual differences. To my knowledge, the best discussion of this widely known secret is in Luck (2005). He describes how fairly striking individual differences exist in even the early sensory and perceptual ERP components, like the P1 and N1. These individual differences can be directly appreciated if we consult earlier ERP studies in which the data from each participant are shown (e.g., Hillyard et al., 1973). The individual differences that we observe cannot be due simply to excess noise in our data acquisition systems or analysis procedures, because these differences are very reliable across recording sessions with the same observer.

In ERP studies, we seek to average together waveforms from a large enough sample of observers that our results generalize to the entire population from which they are drawn. However, the underlying cause of the observed individual differences could either be trivial or integral for our understanding of the cognitive process that a given component indexes.

One trivial explanation of individual differences in the morphology of ERP components is that the observed differences are simply due to the underlying pattern of cortical folding in each participant. According to this explanation, all people have fundamentally the same ERP components and cognitive processing mechanisms, but the voltage patterns that we observe at the scalp depend heavily on the folding pattern of the cortical tissue. At a fundamental level, we know that the orientation of the gray matter relative to the skull is critically important (Nunez \& Srinivasan, 2006). To put this more concretely, my N1 component might have a small amplitude relative to yours because some of the critical chunks of cortex that generate the N1 are in a sulcus in my brain, whereas they are all on gyri in your brain. Skull thickness and conductivity also vary across individuals and are important for the morphology of ERP components (Hoekema et al., 2003). Cortical folding and the metrics of tissue in the head are two examples of a number of relatively uninteresting possible explanations for the individual differences in ERP com- ponents that are observed (Nunez \& Srinivasan, 2006). Essentially, these are explanations that propose that the differences are due to geometric noise in our anatomy that is unrelated to how the brain processes information.

Accounts at the other extreme propose that differences in the morphology of ERP components across individuals may tell us about the fundamental differences in information processing that endow each of us with unique cognitive abilities. An example of this type of proposal is the recent work of Vogel and colleagues (Fukuda \& Vogel, 2009; Vogel \& Machizawa, 2004; Vogel, McCollough, \& Machizawa, 2005). Their work shows that the amplitude of the CDA predicts the individual observer's ability to store information in visual working memory and avoid distraction from irrelevant stimuli. We may be at an exciting time when we have the tools and necessary theoretical motivation to determine how much of the individual differences in ERP components is due to uninteresting geometry versus how much is due to factors that are critical to our understanding of how the mind works.

The known individual differences in ERP component morphology have important implications at a practical level. When we begin running participants using a new neuroscience technique or behavioral paradigm, it would be great if we could run a couple of pilot participants and know whether the results that we obtain were going to be interpretable. However, this is sometimes not possible with ERP experiments because of the individual differences described above. One or more of my pilot participants might not have the component that I am predicting will be modulated by the task manipulations. The timeless problems associated with small samples and unknown effect sizes can be exacerbated by presenting each participant with an insufficient number of trials to obtain clean data, as was discussed earlier. For this reason, when working with a number of unknown factors, I believe that the best pilot experiment is just to run Experiment 1 of the study. However, when you are operating with questions and tools that you better understand, it can be possible to perform pilot studies with a fairly modest number of participants.

\section{Known Unknowns}

How can the temporal resolution of ERPs be at the millisecond level but the spatial resolution be not even known? This is because if the geometry of the cortex generating a given ERP component is just right relative to the skull and all other cortical generators, the spatial resolution may be fairly precise (on the order of several cubic centimeters; Nunez \& Srinivasan, 2006). Often, we implicitly assume that if a component has a relatively focused scalp topography and is maximal at a given electrode site (e.g., Pz in the standard 10/20 system), it is generated by the cortex just beneath the electrode (e.g., posterior parietal cortex; see Homan, Herman, \& Purdy, 1987; Koessler et al., 2009; Steinmetz, Fürst, \& Meyer, 1989). However, given that we do not know the number of simultaneously active neural generators that contribute to a given ERP component or effect, it is unknown whether the relevant activity that we are measuring is generated near the electrode or across the entire cortical sheet. For example, consider the case in 
which you have two neural generators active at the same time but of opposite polarity. Given this configuration, the voltage measured on the distal scalp will be 0 . Now imagine one large dipole of one orientation and two smaller but equal dipoles of the opposite orientation. It should be obvious at this point, as it was to Helmholtz (1853), that there is theoretically an infinite number of ways to measure $0 \mathrm{~V}$ outside the volume conductor of the head, despite abundant electrical activity inside of it. Now imagine how many possible dipole configurations generated by chunks of active cortex could be giving you the voltage distribution that you observe for any ERP component.

The difficulty of solving the problem of localizing ERP effects within the brain has resulted in researchers' battling the problem on at least four fronts simultaneously. On one of these battlefronts, the weapons of increasingly dense electrode arrays and computer modeling are used. The hope is that with sufficiently dense arrays of electrodes and models constrained by structural imaging of the brain, the number of possible generators will be sufficiently small as to be tractable. On the second front, combined imaging and electrophysiological recordings are used. This seems like the best of both worlds. fMRI has excellent spatial resolution but slow temporal resolution, whereas ERPs have excellent temporal resolution but poor to unknown spatial precision. However, even when these two data sets are collected at the same time, it is still difficult to confidently link a fast ERP effect (e.g., $100 \mathrm{msec}$ long) that occurs just after the stimulus appears $(>1 \mathrm{sec})$ with a slow BOLD response measured long after the stimulus appeared $(\sim 10 \mathrm{sec})$. We can show support for a functional relationship by correlating the signals across multiple levels of an independent variable or on a trial- by-trial or block-by-block basis. But the signal-to-noise ratios of the signals can make these analyses difficult and even in the best circumstances do not provide evidence for a causal relationship between localized BOLD activity and ERP component effects. In the third approach, researchers have measured ERPs from patients with specific brain lesions (Knight, 1991). This combination of methods has the power of affording causal inferences but also has the ambiguities inherent to neuropsychological studies because of possible reorganization and because lesions can damage critical fibers of passage. The advent of transcranial magnetic stimulation (TMS) has provided a way to perform experiments in humans with virtual, reversible lesions while recording ERPs (e.g., Driver, Blankenburg, Bestmann, Vanduffel, \& Ruff, 2009; Fuggetta, Pavone, Walsh, Kiss, \& Eimer, 2006). In addition, a number of the technical challenges of combining TMS with ERPs appear to have been addressed (see Thut, Ives, Kampmann, Pastor, \& Pascual-Leone, 2005). Using the fourth approach, researchers have sought to record ERPs from animals that can be linked to those found in humans and then to localize the neural generators of those components in the animal models with invasive techniques (e.g., Cohen, Heitz, Schall, \& Woodman, 2009; Mehta, Ulbert, \& Schroeder, 2000a, 2000b; Schroeder, Tenke, \& Givre, 1992; Schroeder, Tenke, Givre, Arezzo, \& Vaughan, 1991). Personally, I have great hope for this approach (Cohen et al., 2009; Woodman, in press; Woodman, Kang, Rossi, $\&$ Schall, 2007). The initial article showing that monkeys had a P3 component similar to that of humans identified the potential for such work to be combined with causal manipulations such as lesion and inactivation studies (Arthur \& Starr, 1984; Pineda, Foote, \& Neville, 1989).

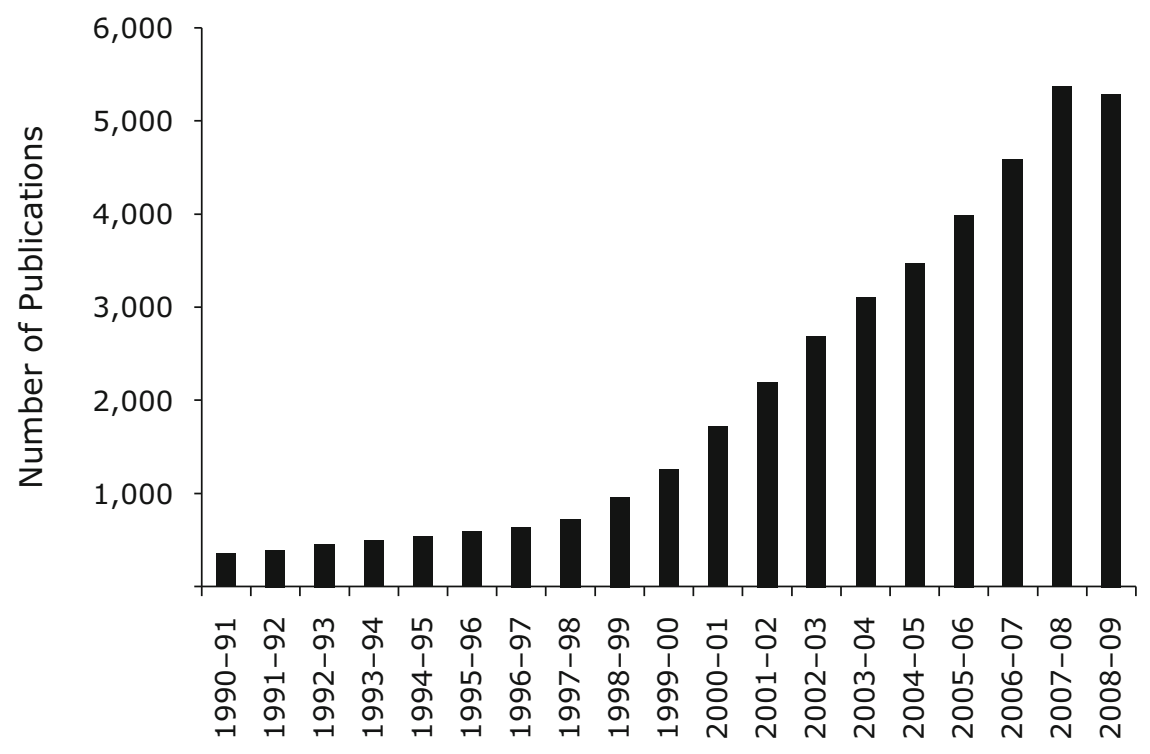

Year of Publication

Figure 5. Number of event-related potential reports by year of publication. Data derived from PsycINFO searches for the terms event-related potential, ERP, or evoked potential in any search field. 
The final issue that I will mention has been the topic of frequent discussions with colleagues and in manuscripts. This is the question of whether there are distinct ERP signatures of feedback processes. The role of feedback between regions of the brain has become increasingly important in theories of attention and perceptual processing (e.g., Di Lollo, Enns, \& Rensink, 2000; Lamme \& Roelfsema, 2000). Although ERPs have great temporal resolution, it is very difficult to determine which ERP components are due to feedforward processing and which have contributions from feedback.

The primary variable that researchers use to infer that certain effects are due to feedforward rather than feedback processes in the brain is the absolute timing of the modulation. We can reasonably expect that the earliest ERP components elicited following the presentation of stimuli are due to feedforward processing of the representations of the stimuli. For example, both the $\mathrm{C} 1$ and $\mathrm{P} 1$ components occur early enough that ERP researchers assume that they are wholly or primarily due to the feedforward sweep of activity through the sensory pathway (e.g., Zhang \& Luck, 2008). In contrast, other components have a timing and distribution that suggest that they are largely due to feedback. An example is the N2pc component that occurs approximately $200 \mathrm{msec}$ poststimulus and has a scalp distribution that suggests that it might be generated by activity in the ventral visual stream. Given that this attention effect occurs about 30$130 \mathrm{msec}$ after the first attentional modulations of ERP components with similar distributions, Luck and Hillyard (1994b) proposed that the N2pc is due to feedback from an attentional control structure, like the pulvinar (or the frontal eye field; see Cohen et al., 2009). Beyond using logical arguments like this, the methods needed to demonstrate that certain ERP effects of interest are due to feedback can be technically challenging (Cohen et al., 2009; Martinez et al., 1999). I wish that the interesting questions regarding the role of feedback were more easily testable using only the ERP technique. As with behavioral studies of perception and attention, the best way to effectively use ERP studies to answer questions about feedback processes is with clever logic and experimental designs.

\section{Summary}

The goal of this brief introduction to the ERP technique was to familiarize cognitive scientists who study perception and attention with the basics of interpreting findings from ERP experiments. My approach was to share my perspective on the topics of ERP methodology that I deal with most frequently. I discussed a number of issues that I hope will help those running ERP experiments, readers interpreting ERP findings, and researchers dealing with ERP data for first time. Despite the advent of new technologies, studies of attention and perception still rely heavily on the ERP technique to test hypotheses and theories about how the brain rapidly processes information. In fact, Figure 5 shows that during the last 10 years, the number of articles in which findings from ERP experiments have been reported or referred to has increased by approximately
$500 \%$. It is evident that the impact and volume of research using the ERP technique continues to increase. This makes it particularly important to be a savvy consumer of ERP research, even if it is not a methodology that you utilize in your own work.

\section{AUTHOR NOTE}

I thank Steve Luck for feedback on an earlier draft of this tutorial. Min-Suk Kang, Nancy Carlisle, and Melonie Williams provided useful discussions. Jason Arita and Michelle Young aided in the preparation of the figures. Michael Bach, Martin Eimer, and Trafton Drew gave me excellent comments and suggestions as reviewers. G.F.W. is supported by the NIH (NEI, R01EY019882 \& P30EY008126). Correspondence concerning this article should be addressed to G. F. Woodman, Department of Psychology, Vanderbilt University, PMB 407817, 2301 Vanderbilt Place, Nashville, TN 37240-7817 (e-mail: geoffrey.f.woodman@, vanderbilt.edu).

\section{REFERENCES}

Adrian, E. D., \& Yamagiwa, K. (1935). The origin of the Berger rhythm. Brain, 58, 323-351.

Arthur, D. L., \& STARr, A. (1984). Task-relevant late positive component of the auditory event-related potential in monkeys resembles P300 in humans. Science, 223, 186-188.

BACH, M. (1998). Electroencephalogram (EEG). In G. K. von Schulthess \& J. Hennig (Eds.), Functional imaging: Principles and methodology (pp. 391-408). Philadelphia: Lippincott-Raven.

BACH, M., \& MeIgen, T. (1992). Electrophysiological correlates of texture segregation in the human visual evoked potential. Vision Research, 32, 417-424.

Berg, P., \& Scherg, M. (1994). A multiple source approach to the correction of eye artifacts. Electroencephalography \& Clinical Neurophysiology, 90, 229-241.

Berger, H. (1929). Über das Elektrenkephalogramm des Menschen. Archiv für Psychiatrie \& Nervenkrankheiten, 87, 527-570.

Brown, R. J., \& NorcIA, A. M. (1997). A method for investigating binocular rivalry in real-time with steady-state VEP. Vision Research, 37, 2401-2408.

Brunia, C. H. M., van Boxtel, G. J. M., \& Böcker, K. B. E. (in press). Negative slow waves as indices of anticipation: The bereitshaftspotential, the contingent negative variation, and the stimulus preceding negativity. In S. J. Luck \& E. Kappenman (Eds.), Oxford handbook of event-related potential components. New York: Oxford University Press.

Clark, V. P., FAN, S., \& Hillyard, S. A. (1995). Identification of early visually evoked potential generators by retinotopic and topographic analyses. Human Brain Mapping, 2, 170-187.

Clark, V. P., \& Hillyard, S. A. (1996). Spatial selective attention affects early extrastriate but not striate components of the visual evoked potential. Journal of Cognitive Neuroscience, 8, 387-402.

Cohen, J. Y., Heitz, R. P., Schall, J. D., \& Woodman, G. F. (2009). On the origin of event-related potentials indexing covert attentional selection during visual search. Journal of Neurophysiology, 102, 2375-2386.

Coles, M. G. H. (1989). Modern mind-brain reading: Psychophysiology, physiology, and cognition. Psychophysiology, 26, 251-269.

Coles, M. G. H., Gratton, G., \& Donchin, E. (1988). Detecting early communication: Using measures of movement-related potentials to illuminate human information processing. Biological Psychology, 26, 69-89.

Cooper, R., Winter, A. L., Crow, H. J., \& Walter, W. G. (1965) Comparison of subcortical, cortical, and scalp activity using chronically indwelling electrodes in man. Electroencephalography \& Clinical Neurophysiology, 18, 217-228.

Crevits, L., van Lith, G., \& ViIfvinkel-Bruinenga, S. (1982). On and off contribution to the combined occipital on-off response to a pattern stimulus. Ophthalmologica, 184, 169-173.

Crowley, K. E., \& Colrain, I. M. (2004). A review of the evidence for P2 being an independent component process: Age, sleep and modality. Clinical Neurophysiology, 115, 732-744. 
DAvis, H. (1964). Enhancement of evoked cortical potential in humans related to a task requiring a decision. Science, 145, 182-183.

DAvis, P. A. (1939). Effects of acoustic stimuli on the waking human brain. Journal of Neurophysiology, 2, 494-499.

Dawson, G. D. (1954). A summation technique for the detection of small evoked potentials. Electroencephalography \& Clinical Neurophysiology, 6, 65-84.

Desmedt, J. E., Huy, N. T., \& Bourguet, M. (1983). The cognitive P40, N60 and P100 components of somatosensory evoked potentials and the earliest electrical signs of sensory processing in man. Electroencephalography \& Clinical Neurophysiology, 56, 272-282.

DIEN, J. (1998). Issues in the application of the average reference: Review, critiques, and recommendations. Behavior Research Methods, Instruments, \& Computers, 30, 34-43.

Di Lollo, V., Enns, J. T., \& Rensink, R. A. (2000). Competition for consciousness among visual events: The psychophysics of reentrant visual processes. Journal of Experimental Psychology: General, 129, 481-507.

Donchin, E. (1981). Surprise! ... Surprise? Psychophysiology, 18, 493513.

Donchin, E., \& Cohen, L. (1967). Averaged evoked potentials and intramodality selective attention. Electroencephalography \& Clinical Neurophysiology, 22, 537-546.

Donchin, E., \& Heffley, E. (1975). Minicomputers in the signalaveraging laboratory. American Psychologist, 30, 299-312.

Donchin, E., \& LindSLEY, D. B. (EDS.) (1969). Average evoked potentials, methods, results, and evaluations. Washington, DC: U.S. Government Printing Office.

Driver, J., Blankenburg, F., Bestmann, S., Vanduffel, W., \& Ruff, C. C. (2009). Concurrent brain-stimulation and neuroimaging for studies of cognition. Trends in Cognitive Sciences, 13, 319-327.

Duncan-Johnson, C. C., \& Donchin, E. (1979). The time constant in P300 recording. Psychophysiology, 16, 53-55.

Ebersole, J. S. (1997). Defining epileptic foci: Past, present, future. Journal of Clinical Neurophysiology, 14, 470-483.

EIMER, M. (1996). The N2pc component as an indicator of attentional selectivity. Electroencephalography \& Clinical Neurophysiology, 99 , 225-234.

EIMER, M. (1998). Does the face-specific N170 component reflect the activity of a specialized eye processor? NeuroReport, 9, 2945-2948.

Ellemberg, D., Hammarrenger, B., Lepore, F., Roy, M.-S., \& GuilLEMOT, J.-P. (2001). Contrast dependency of VEPs as a function of spatial frequency: The parvocellular and magnocellular contributions to human VEPs. Spatial Vision, 15, 99-111.

Estevez, O., \& Spekreisse, H. (1974). Relationship between pattern appearance-disappearance and pattern reversal responses. Experimental Brain Research, 19, 233-238.

Falkenstein, M., Hoormann, J., Christ, S., \& Hohnsbein, J. (2000). ERP components of reaction errors and their functional significance: A tutorial. Biological Psychology, 51, 87-107.

Felleman, D. J., \& Van Essen, D. C. (1991). Distributed hierarchical processing in the primate cerebral cortex. Cerebral Cortex, 1, 1-47.

Folstein, J. R., \& Van Petten, C. (2008). Influence of cognitive control and mismatch on the N2 component of the ERP: A review. Psychophysiology, 45, 152-170.

Fox, S. S., \& O'BRIEN, J. H. (1965). Duplication of evoked potential waveform by curve of probability of firing of a single cell. Science, 147, 889-890.

Fuggetta, G., Pavone, E. F., Walsh, V., Kiss, M., \& Eimer, M. (2006). Cortico-cortical interactions in spatial attention: A combined ERP/ TMS study. Journal of Neurophysiology, 95, 3277-3280.

FUKUDA, K., \& Vogel, E. K. (2009). Human variation in overriding attentional capture. Journal of Neuroscience, 29, 8726-8733.

Galambos, R., \& Jahasz, G. (1997). The contribution of glial cells to spontaneous and evoked potentials. International Journal of Psychophysiology, 26, 229-236.

Galambos, R., \& Sheatz, G. C. (1962). An electroencephalography study of classical conditioning. American Journal of Physiology, 203 , 173-184.

Gehring, W. J., Liu, Y., Orr, J. M., \& Carp, J. (in press). The errorrelated negativity (ERN/Ne). In S. J. Luck \& E. Kappenman (Eds.), Oxford handbook of event-related potential components. New York: Oxford University Press.
HANDy, T. C. (2005). Event-related potentials: A methods handbook. Cambridge, MA: MIT Press.

Heinze, H. J., Mangun, G. R., Burchert, W., Hinrichs, H., Scholz, M., Münte, T. F., ET AL. (1994). Combined spatial and temporal imaging of brain activity during visual selective attention in humans. Nature, 372, 543-546.

Heinze, H. J., Mangun, G. R., \& Hillyard, S. A. (1990). Visual eventrelated potentials index perceptual accuracy during attention to bilateral stimuli. In C. H. M. Brunia, A. W. K. Gaillard, \& A. Kok (Eds.), Psychophysiological brain research (pp. 196-202). Tilburg: Tilburg University Press.

Helmholtz, H. von (1853). Über einige Gesetze der Vertheilung elektrischer Ströme in körperlichen Leitern mit Anwendung auf die thierisch-elektrischen Versuche. Annalen der Physik \& Chemie, 89, 211-233, 354-377.

Hillyard, S. A., \& Galambos, R. (1970). Eye movement artifact in the CNV. Electroencephalography \& Clinical Neurophysiology, 28, $173-182$

Hillyard, S. A., Hink, R. F., Schwent, V. L., \& Picton, T. W. (1973). Electrical signs of selective attention in the human brain. Science, 182, $177-180$

Hillyard, S. A., \& Picton, T. W. (1978). On and off components in the auditory evoked potential. Perception \& Psychophysics, 24, 391-398.

Hillyard, S. A., \& Picton, T. W. (1987). Electrophysiology of cognition. In F. Plum (Ed.), Handbook of physiology: Sec. 1. The nervous system: Vol. 5. Higher functions of the brain, part 2 (pp. 519-584). Bethesda, MD: Waverly Press.

Hillyard, S. A., Vogel, E. K., \& LuCK, S. J. (1998). Sensory gain control (amplification) as a mechanism of selective attention: Electrophysiological and neuroimaging evidence. Philosophical Transactions of the Royal Society B, 353, 1257-1270.

Hoekema, R., Wieneke, G. H., Leitten, F. S. S., van Veelen, C. W. M., van RiJen, P. C., Huiskamp, G. J. M., ET AL. (2003). Measurement of the conductivity of skull temporarily removed during epilepsy surgery. Brain Topography, 16, 29-38.

Hoffman, J. E., \& Subramaniam, B. (1995). The role of visual attention in saccadic eye movements. Perception \& Psychophysics, $\mathbf{5 7}$ 787-795.

Homan, R. W., Herman, J., \& Purdy, P. (1987). Cerebral location of international 10-20 system electrode placement. Electroencephalography \& Clinical Neurophysiology, 66, 376-382.

Ille, N., Berg, P., \& Scherg, M. (2002). Artifact correction of the ongoing EEG using spatial filters based on artifact and brain signal topographies. Journal of Clinical Neurophysiology, 19, 113-124.

JASPER, H. H. (1937). Electrical signs of cortical activity. Psychological Bulletin, 34, 411-481.

JASPER, H. H. (1948). Charting the sea of brain waves. Science, 108, 343-347.

JASPER, H. H. (1958). The ten-twenty electrode system of the International Federation. Electroencephalography \& Clinical Neurophysiology, 10, 371-375.

JefFREYs, D. A., \& AXFord, J. G. (1972). Source locations of patternspecific components of human visual evoked potentials: I. Components of striate cortical origin. Experimental Brain Research, 16, $1-21$

Johnson, R., JR. (1986). A triarchic model of P300 amplitude. Psychophysiology, 23, 367-384.

Kiesel, A., Miller, J. O., Jolicceur, P., \& Brisson, B. (2008). Measurement of ERP latency differences: A comparison of singleparticipant and jackknife-based scoring methods. Psychophysiology, $45,250-274$

Klaver, P., Talsma, D., Wijers, A. A., Heinze, H. J., \& Mulder, G. (1999). An event-related brain potential correlate of visual short-term memory. NeuroReport, 10, 2001-2005.

KNIGHT, R. T. (1991). Evoked potential studies of attention capacity in human frontal lobe lesions. In H. S. Levin, H. M. Eisenberg, \& A. L. Benton (Eds.), Frontal lobe function and dysfunction (pp. 139-153). New York: Oxford University Press.

Koessler, L., Maillard, L., Benhadid, A., Vignal, J. P., FelBLINGER, J., VeSPIGNANI, H., \& BraUn, M. (2009). Automated cortical projection of EEG sensors: Anatomical correlation via the international 10-10 system. NeuroImage, 46, 64-72.

Kornhuber, H. H., \& DeEcKe, L. (1965). Hirnpotentialanderungen bei 
Wilkurbewegungen und passiven Bewegungen des Menschen: Bereitschaftspotential und reafferente potentials. Pflügers Archiv, 284, 1-17.

Kowler, E., Anderson, E., Dosher, B., \& Blaser, E. (1995). The role of attention in the programming of saccades. Vision Research, 35, 1897-1916.

Kutas, M., McCarthy, G., \& Donchin, E. (1977). Augmenting mental chronometry: The P300 as a measure of stimulus evaluation time. Science, 197, 792-795.

Lamme, V. A. F., \& Roelfsema, P. R. (2000). The distinct modes of vision offered by feedforward and recurrent processing. Trends in Neurosciences, 23, 571-579.

Li, C.-L., McLennan, H., \& Jasper, H. (1952). Brain waves and unit discharge in cerebral cortex. Science, 116, 656-657.

Lins, O. G., Picton, T. W., Berg, P., \& Scherg, M. (1993). Ocular artifacts in EEG and event-related potentials I: Scalp topography. Brain Topography, 6, 51-63.

Logothetis, N. K., Pauls, J., Augath, M. A., Trinath, T., \& OelterMANN, A. (2001). Neurophysiological investigation of the basis of the fMRI signal. Nature, 412, 150-157.

Lu, Z.-L., Williamson, S. J., \& Kaufman, L. (1992). Behavioral lifetime of human auditory sensory memory predicted by physiological measures. Science, 258, 1668-1670.

LUCK, S. J. (1995). Multiple mechanisms of visual-spatial attention: Recent evidence from human electrophysiology. Behavioural Brain Research, 71, 113-123.

LUCK, S. J. (2004). Ten simple rules for designing ERP experiments. In T. C. Handy (Ed.), Event-related potentials: A methods handbook. Cambridge, MA: MIT Press.

LUCK, S. J. (2005). An introduction to the event-related potential technique. Cambridge, MA: MIT Press

LUCK, S. J. (in press). ERP components in the perception of multipleelement stimulus arrays. In S. J. Luck \& E. Kappenman (Eds.), Oxford handbook of event-related potential components. New York: Oxford University Press.

LUCK, S. J., \& Hillyard, S. A. (1994a). Electrophysiological correlates of feature analysis during visual search. Psychophysiology, 31, 291308

LuCK, S. J., \& Hillyard, S. A. (1994b). Spatial filtering during visual search: Evidence from human electrophysiology. Journal of Experimental Psychology: Human Perception \& Performance, 20, 10001014.

Makeig, S., Westerfield, M., Jung, T.-P., Enghoff, S., TownSend, J., Courchesne, E., \& Sejnowski, T. J. (2002). Dynamic brain sources of visual evoked responses. Science, 295, 690-694.

Mangun, G. R., \& Hillyard, S. A. (1990). Electrophysiological studies of visual selective attention in humans. In A. B. Scheibel \& A. F. Wechsler (Eds.), Neurobiology of higher cognitive function (pp. 271295). New York: Guilford.

Martinez, A., Anllo-Vento, L., Sereno, M. I., Frank, L. R., BuXTON, R. B., Dubowitz, D. J., ET AL. (1999). Involvement of striate and extrastriate visual cortical areas in spatial attention. Nature Neuroscience, 2, 364-369.

McDonald, J. J., Teder-Sälejärvi, W. A., \& Hillyard, S. A. (2000). Involuntary orienting to sound improves visual perception. Nature, 407, 906-908.

Mehta, A. D., Ulbert, I., \& Schroeder, C. E. (2000a). Intermodal selective attention in monkeys: I. Distribution and timing of effects across visual areas. Cerebral Cortex, 10, 343-358.

Mehta, A. D., Ulbert, I., \& Schroeder, C. E. (2000b). Intermodal selective attention in monkeys: II. Physiological mechanisms of modulation. Cerebral Cortex, 10, 359-370.

Miller, J. O., \& HaCKLEY, S. A. (1992). Electrophysiological evidence for temporal overlap among contingent mental processes. Journal of Experimental Psychology: General, 121, 195-209.

NÄÄTÄNEN, R. (1975). Selective attention and evoked potentials in humans: A critical review. Biological Psychology, 2, 237-307.

NäÄTÄNEN, R., Gaillard, A. W. K., \& MäntYsalo, S. (1978). Early selective-attention effect on evoked potential reinterpreted. Acta Psychologica, 42, 313-329.

NÄÄTÄNEN, R., \& MichiE, P. T. (1979). Early selective attention effects on the evoked potential: A critical review and reinterpretation. Biological Psychology, 8, 81-136.
NäÄtÄnen, R., \& Picton, T. (1987). The N1 wave of the human electric and magnetic response to sound: A review and an analysis of the component structure. Psychophysiology, 24, 375-425.

Nelson, D. A., \& Lassman, F. M. (1973). Combined effects of recovery period and stimulus intensity on the human auditory evoked vertex response. Journal of Speech \& Hearing Research, 16, 297-308.

NunEz, P. L. (1981). Electric fields of the brain. New York: Oxford University Press.

Nunez, P. L., \& SRInivasan, R. (2006). Electric fields of the brain: The neurophysics of EEG (2nd ed.). Oxford: Oxford University Press.

Osman, A., Bashore, T. R., Coles, M. G., Donchin, E., \& Meyer, D. E. (1992). On the transmission of partial information: Inferences from movement-related brain potentials. Journal of Experimental Psychology: Human Perception \& Performance, 18, 217-232.

Otten, L. J., Quayle, A. H., Akram, S., Ditewig, T. A., \& Rugg, M. D. (2006). Brain activity before an event predicts later recollection. Nature Neuroscience, 9, 489-491.

Palva, S., \& Palva, J. M. (2007). New vistas for alpha-frequency band oscillations. Trends in Neurosciences, 30, 150-158.

Perez, V. B., \& Vogel, E. K. (in press). What ERPs can tell us about working memory. In S. J. Luck \& E. Kappenman (Eds.), Oxford handbook of event-related potential components. New York: Oxford University Press.

Pfurtscheller, G., Stancák, A., JR., \& Neuper, C. (1996). Eventrelated synchronization (ERS) in the alpha band-an electrophysiological correlate of cortical idling: A review. International Journal of Psychophysiology, 24, 39-46.

Picton, T. W., Woods, D. L., \& Proulx, G. B. (1978a). Human auditory sustained potentials: I. The nature of the response. Electroencephalography \& Clinical Neurophysiology, 45, 186-197.

Picton, T. W., Woods, D. L., \& ProulX, G. B. (1978b). Human auditory sustained potentials: II. Stimulus relationships. Electroencephalography \& Clinical Neurophysiology, 45, 198-210.

Pineda, J. A., Foote, S. L., \& Neville, H. J. (1989). Effects of locus coeruleus lesions on auditory, long-latency, event-related potentials in monkey. Journal of Neuroscience, 9, 81-93.

PoLICH, J. (in press). Neuropsychology of P300. In S. J. Luck \& E. Kappenman (Eds.), Oxford handbook of event-related potential components. New York: Oxford University Press.

PRATT, H. (in press). Sensory ERP components. In S. J. Luck \& E. Kappenman (Eds.), Oxford handbook of event-related potential components. New York: Oxford University Press.

Pritchard, W. S., Shappell, S. A., \& Brandt, M. W. (1991). Psychophysiology N200/N400: A review and classification scheme. In J. R. Jennings, P. K. Ackles, \& M. G. H. Coles (Eds.), Advances in psychophysiology (Vol. 4, pp. 43-106). London: Jessica Kingsley.

REGAN, D. (1989). Human brain electrophysiology: Evoked potentials and evoked magnetic fields in science and medicine. New York: Elsevier.

Renault, B., Ragot, R., Lesevre, N., \& Remond, A. (1982). Onset and offset of brain events as indices of mental chronometry. Science, 215, 1413-1415.

Rossion, B., \& JACQUes, C. (in press). N170. In S. J. Luck \& E. Kappenman (Eds.), Oxford handbook of event-related potential components. New York: Oxford University Press.

RugG, M. D., \& Coles, M. G. H. (Eds.) (1995). Electrophysiology of mind. New York: Oxford University Press.

Schroeder, C. E., Tenke, C. E., \& Givre, S. J. (1992). Subcortical contributions to the surface-recorded flash-VEP in the awake macaque. Electroencephalography \& Clinical Neurophysiology, 84, 219-231.

Schroeder, C. E., Tenke, C. E., Givre, S. J., Arezzo, J. C., \& Vaughan, H. G., JR. (1991). Striate cortical contribution to the surface-recorded pattern-reversal VEP in the alert monkey. Vision Research, 31, 1143-1157.

Shah, A. S., Bressler, S. L., Knuth, K. H., Ding, M., Mehta, A. D., Ulbert, I., \& Schroeder, C. E. (2004). Neural dynamics and the fundamental mechanisms of event-related brain potentials. Cerebral Cortex, 14, 476-483.

Smulders, F. T. Y., \& Miller, J. O. (in press). The lateralized readiness potential. In S. J. Luck \& E. Kappenman (Eds.), Oxford handbook of event-related potential components. New York: Oxford University Press.

Spackman, L., Boyd, S., \& Towell, T. (2006). Identification and char- 
acterization of somatosensory off responses. Brain Research, 1114, 53-62.

Spong, P., Haider, M., \& LindSLey, D. B. (1965). Selective attentiveness and cortical evoked responses to visual and auditory stimuli. Science, 148, 395-397.

Steinmetz, H., Fürst, G., \& Meyer, B.-U. (1989). Craniocerebral topography within the international 10-20 system. Electroencephalography \& Clinical Neurophysiology, 72, 499-506.

SutTon, S. (1979). P300-Thirteen years later. In H. Begleiter (Ed.), Evoked brain potentials and behavior (pp. 107-126). New York: Plenum.

Sutton, S., Braren, M., Zubin, J., \& John, E. R. (1965). Evoked potential correlates of stimulus uncertainty. Science, 150, 1187-1188

Sutton, S., Tueting, P., Zubin, J., \& John, E. R. (1967). Information delivery and the sensory evoked potential. Science, 155, 1436-1439.

Thierry, G., Martin, C. D., Downing, P., \& Pegna, A. J. (2007). Controlling for interstimulus perceptual variance abolishes N170 face selectivity. Nature Neuroscience, 10, 505-511.

Thut, G., Ives, J. R., Kampmann, F., Pastor, M. A., \& PascualLEONE, A. (2005). A new device and protocol for combining TMS and online recordings of EEG and evoked potentials. Journal of Neuroscience Methods, 141, 207-217.

UNGERLEIDER, L. G., \& MishKIN, M. (1982). Two cortical visual systems. In D. J. Ingle, R. J. W. Mansfield, \& M. A. Goodale (Eds.), The analysis of visual behavior (pp. 549-586). Cambridge, MA: MIT Press.

Vogel, E. K., \& LUCK, S. J. (2000). The visual N1 component as an index of a discrimination process. Psychophysiology, 37, 190-203.

Vogel, E. K., LuCK, S. J., \& ShaPIRO, K. L. (1998). Electrophysiological evidence for a postperceptual locus of suppression during the attentional blink. Journal of Experimental Psychology: Human Perception \& Performance, 24, 1656-1674.

Vogel, E. K., \& MachizaWA, M. G. (2004). Neural activity predicts individual differences in visual working memory capacity. Nature, 428, 748-751

Vogel, E. K., McCollough, A. W., \& Machizawa, M. G. (2005). Neural measures reveal individual differences in controlling access to working memory. Nature, 438, 500-503.

Walter, W. G. (1938). Critical review: The technique and application of electro-encephalography. Journal of Neurology \& Psychiatry, $\mathbf{1}$, 359-385.

Walter, W. G., Cooper, R., Aldridge, V. J., McCallum, W. C., \& Winter, A. L. (1964). Contingent negative variation: An electric sign of sensorimotor association and expectancy in the human brain. Nature, 203, 380-384.

WoODMAN, G. F. (in press). Homologues of human event-related potential components in nonhuman primates. In S. J. Luck \& E. Kappenman (Eds.), Oxford handbook of event-related potential components. New York: Oxford University Press.

Woodman, G. F., Arita, J. T., \& LUCK, S. J. (2009). A cuing study of the N2pc component: An index of attentional deployment to objects rather than spatial locations. Brain Research, 1297, 101-111.

Woodman, G. F., Kang, M.-S., Rossi, A. F., \& Schall, J. D. (2007). Nonhuman primate event-related potentials indexing covert shifts of attention. Proceedings of the National Academy of Sciences, 104, $15111-15116$

Woodman, G. F., \& LucK, S. J. (1999). Electrophysiological measurement of rapid shifts of attention during visual search. Nature, $\mathbf{4 0 0}$, 867-869.

Woodman, G. F., \& Luck, S. J. (2003a). Dissociations among atten- tion, perception, and awareness during object-substitution masking. Psychological Science, 14, 605-611.

Woodman, G. F., \& LucK, S. J. (2003b). Serial deployment of attention during visual search. Journal of Experimental Psychology: Human Perception \& Performance, 29, 121-138.

Woods, D. L., Courchesne, E., Hillyard, S. A., \& Galambos, R. (1980). Recovery cycles of event-related potentials in multiple detection tasks. Electroencephalography \& Clinical Neurophysiology, 50, 335-347.

Woods, D. L., Hillyard, S. A., Courchesne, E., \& Galambos, R. (1980). Electrophysiological signs of split-second decision-making. Science, 207, 655-657.

Yuval-Greenberg, S., Tomer, O., Keren, A. S., Nelken, I., \& Deouell, L. Y. (2008). Transient induced gamma-band response in EEG as a manifestation of miniature saccades. Neuron, 58, 429441

ZHANG, W., \& LucK, S. J. (2008). Feature-based attention modulates feedforward visual processing. Nature Neuroscience, 12, 24-25.

\section{NOTES}

1. One of the critical issues covered in these more comprehensive sources is the relationship between the term event-related potential and other terms, such as evoked potential, visual evoked potential, steady state visual evoked potential, and so forth.

2. ERP components are typically named using a polarity ( $\mathrm{N}$ for negative and $\mathrm{P}$ for positive) and ordinal (1 for first, 2 for second, etc.) nomenclature. The latter convention is due to absolute timing differences being fairly common in many of the components across participants and paradigms. However, some researchers prefer to use a temporal label following the indication of polarity (e.g., P300 instead of P3). Finally, some ERP components have been named using a more descriptive label and its acronym (e.g., lateralized readiness potential and LRP). As a result, care must be taken to relate findings from different studies using different nomenclatures but really measuring the same component. Table 1 is provided to make some connections between the same or similar components described with different nomenclatures.

3. One sarcastic comment that ERP researchers often utter is that the participants may have had ESP (i.e., extrasensory perception) when they observe prestimulus activity that discriminates between the stimuli or trial types that have yet to occur. Indeed, the ERP technique could be a good way of testing individuals claiming to have such abilities. In the realm of cognitive neuroscience, in which no solid evidence for ESP exists, such comments are obviously criticisms of the signal-to-noise ratio inherent to the data.

4. Although I describe alpha-band activity as noise, it is possible that the oscillations in this frequency band are what we actually care about and are studying. This would account for why many of the ERP components that we study have most of their content arising from the 8- to $12-\mathrm{Hz}$ frequency band (Makeig et al., 2002). Research into the fundamental nature of the activity underlying ERP components continues (e.g., Palva \& Palva, 2007; Shah et al., 2004). It is sufficient to say that a significant portion of the activity of the brain is not related to processing stimuli in the task that the experimenter is interested in. Because the alpha band is one of the frequency bands that dominate the raw EEG, its ubiquitous presence is probably both treasure and trash.

(Manuscript received March 26, 2010; revision accepted for publication June 12, 2010.) 